2-D or not 2-D, that is the question: A Northern California test

K. Mayeda, L. Malagnini, W. S. Phillips, W. R. Walter, D. Dreger

June 7, 2005

Seismic Research Review

Palm Springs, CA, United States

September 19, 2005 through September 23, 2005 
This document was prepared as an account of work sponsored by an agency of the United States Government. Neither the United States Government nor the University of California nor any of their employees, makes any warranty, express or implied, or assumes any legal liability or responsibility for the accuracy, completeness, or usefulness of any information, apparatus, product, or process disclosed, or represents that its use would not infringe privately owned rights. Reference herein to any specific commercial product, process, or service by trade name, trademark, manufacturer, or otherwise, does not necessarily constitute or imply its endorsement, recommendation, or favoring by the United States Government or the University of California. The views and opinions of authors expressed herein do not necessarily state or reflect those of the United States Government or the University of California, and shall not be used for advertising or product endorsement purposes. 


\title{
"2-D or not 2-D, that is the question: A Northern California test"
}

\author{
Kevin Mayeda ${ }^{1}$, Luca Malagnini ${ }^{2}$, W. Scott Phillips ${ }^{3}$, William R. Walter ${ }^{1}$, and Douglas \\ Dreger $^{4}$ \\ ${ }^{1}$ Lawrence Livermore National Laboratory \\ 2 Istituto Nazionale di Geofisica e Vulcanolgia, Roma \\ ${ }^{3}$ Los Alamos National Laboratory \\ ${ }^{4}$ University of California, Berkeley
}

\begin{abstract}
Reliable estimates of the seismic source spectrum are necessary for accurate magnitude, yield, and energy estimation. In particular, how seismic radiated energy scales with increasing earthquake size has been the focus of recent debate within the community and has direct implications on earthquake source physics studies as well as hazard mitigation. The 1-D coda methodology of Mayeda et al. [2003] has provided the lowest variance estimate of the source spectrum when compared against traditional approaches that use direct $S$-waves, thus making it ideal for networks that have sparse station distribution. The 1-D coda methodology has been mostly confined to regions of approximately uniform complexity. For larger, more geophysically complicated regions, 2-D path corrections may be required. The complicated tectonics of the northern California region coupled with high quality broadband seismic data provides for an ideal "apples-toapples" test of 1-D and 2-D path assumptions on direct waves and their coda. Using the same station and event distribution, we compared 1-D and 2-D path corrections and observed the following results: (1) 1-D coda results reduced the amplitude variance relative to direct $S$-waves by roughly a factor of $8(800 \%)$; (2) Applying a 2-D correction to the coda resulted in up to $40 \%$ variance reduction from the 1-D coda results; (3) 2-D direct $S$-wave results, though better than 1-D direct waves, were significantly worse than the 1-D coda. We found that coda-based moment-rate source spectra derived from the 2$\mathrm{D}$ approach were essentially identical to those from the 1-D approach for frequencies less than $\sim 0.7-\mathrm{Hz}$, however for the high frequencies $(0.7 \leq f \leq 8.0-\mathrm{Hz})$, the 2-D approach resulted in inter-station scatter that was generally $10-30 \%$ smaller. For complex regions where data are plentiful, a 2-D approach can significantly improve upon the simple 1-D assumption. In regions where only 1-D coda correction is available it is still preferable over 2-D direct wave-based measures.
\end{abstract}

This work was performed under the auspices of the U.S. Department of Energy by the University of California, Lawrence Livermore National Laboratory under Contract No. W-7405-Eng-48. 